\title{
An anatomical study on types of calcaneal facets on talus and co relation between squatting facets and angles of neck
}

\author{
Azra M1, Abhaya Prabhu ${ }^{2, *}$, Balachandra $\mathrm{N}^{3}$ \\ ${ }^{1}$ Assistant Professor, ${ }^{2}$ Tutor, ${ }^{3}$ Professor and HOD, Dept. of Anatomy, East Point College of Medical Sciences and Research \\ Centre, Bangalore, Karnataka, India
}

*Corresponding Author: Abhaya Prabhu

Email: drazramubeen@gmail.com

Received: $24^{\text {th }}$ August, 2018

Accepted: $10^{\text {th }}$ September, 2018

\begin{abstract}
Introduction: Talus is a short, compact bone with muscular attachments. Its head and body are oriented in specific manner. Thus it is subjected to modifications due to change of direction of forces by adapting different postures. Here we present an anatomical study on types of calcaneal articular facet and squatting facet with emphasis on anatomical co-relation of squatting facet with different angles at the neck of Talus.

Materials and Methods: Total 125 dry tali (right-64 and left-61) were studied with no anomalies or pathology. We observed types of calcaneal articular facet on tali, squatting facet, angle of deviation (AD), angle of inclination (AI) were measured. Statistical evaluation of the measured indices was done.

Result and Conclusion: Type II articular facet was the most common type of articular facet on calcaneal surface of tali, $2^{\text {nd }}$ most common being Type I. Squatting facet was observed on $44 \%$ of tali on right side while $37.5 \%$ tali on left side Average AD and AI were 26 and 125 respectively. We found significantly high AI on right sided tali than left sided. No significant co-relation was observed between the $\mathrm{AD}$ and presence or absence of squatting facet but in those tali where squatting facet was present, angle of inclination was significantly larger. We conclude that incidence of calcaneal articular facet and modification on neck of talus (squatting facet with high $\mathrm{AI}$ ) are attributed to differences in race, habitual activities, posture, gait and level of plane used for locomotion by Indian population.
\end{abstract}

Keywords: Tali, Squatting facet, Neck of tali, Articular facet.

\section{Introduction}

Talus is the $2^{\text {nd }}$ largest bone of foot, connecting link between 2 bones of leg and foot thereby involved in weight bearing and transmission of weight to the ground. It has no muscular and tendinous attachment, making it an unstable joint which is more likely to suffer trauma, accidents, or other biomechanical stress resulting in development of arthritic changes in subtalar joint (Verhagen, 1993).

Differences in incidence of different types of articular facets could be due to differences in gait, built structure of population or racial differences. The racial and individual differences of the anatomic construction of tali play a key role on static and kinetic dynamic on the foot. ${ }^{2}$ Therefore, prior knowledge of articulation and various anatomical variations in articulation holds significance not only in delineating underlying pathologies but also in its treatment. Thus, present study was carried out to determine incidence of various types of calcaneal articulating facets in south Indian human tali, variations in both feet and correlate these findings with existing literature.

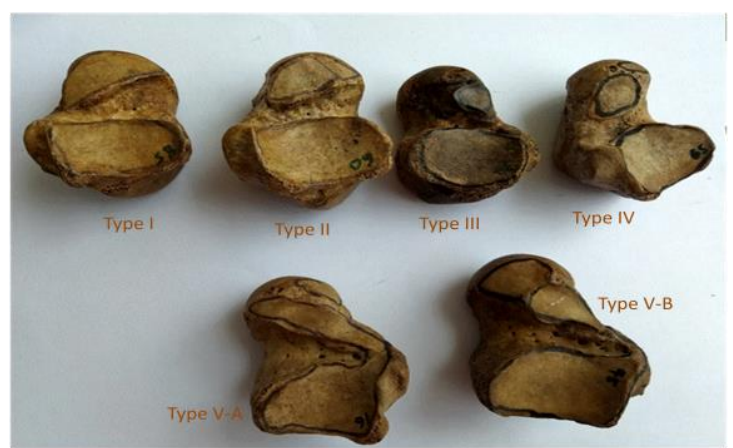

Fig. 1: Different type of articular facets on calcaneal surface of tali

Morphological differences in bones are not only because of racial difference but also due to postural habits adopted by population. One of such habits is squatting, most commonly seen in Indian race. Traction forces on bones of leg and foot because of squatting brings this modification in bones. Such one of the modifications is squatting facet on talus which was described by Thomson ${ }^{3}$ on Australian and Andaman human and other primate specimen.

Charles ${ }^{4}$ suggested that in fetuses and adults the presence of squatting facet on neck of talus provides evidence for inheritance of acquired character. However persistence and development of squatting facet in adult is due to postural life style adopted 
constantly which results in stress on bone leading to its anatomical modification.

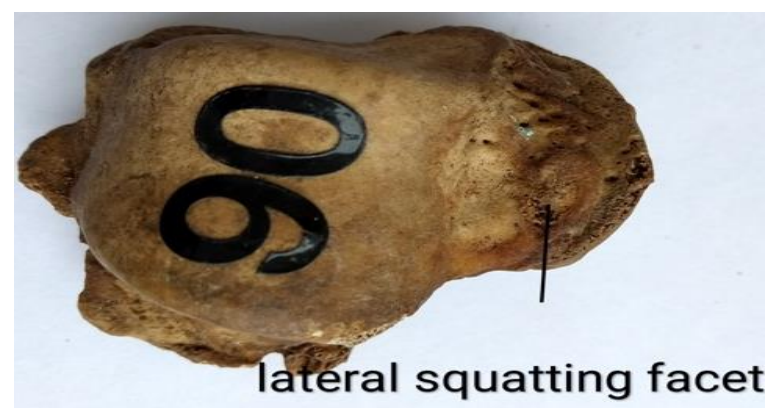

Fig. 2: Lateral squatting facet
AD: In horizontal plane neck shifts medially and makes angle of deviation with long axis of trochlea. AI: In sagittal plane neck is deviated downward in relation to talar body makes an angle of inclination.

The neck is fragile. It is junction between body and head of talus. It has no cartilaginous surface and is perforated by multiple small vascular orifices. Declination angle is bent of neck medially from the axis of the body, bent of neck inferiorly than the body is called an angle of inclination. ${ }^{4}$
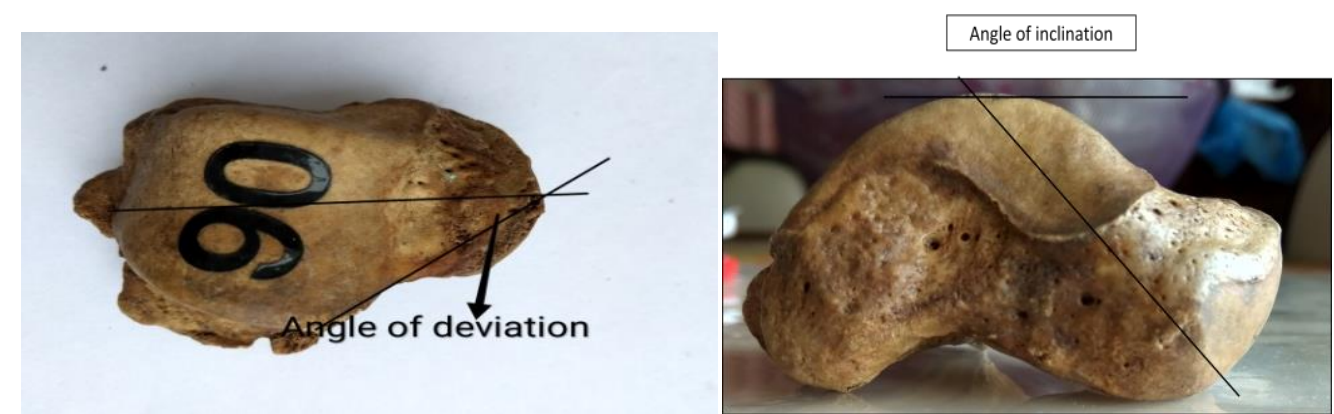

Fig. 3: Angle of deviation/declination and angle of inclination

Paucity of blood supply and no muscular attachment make the talus more prone for injury, makes joints unstable and increases the risk of Osteoarthritis, Psuedoarthrosis and Neurosis. ${ }^{5}$ For radiological and direct intra operative visualization of talar neck position and the angles the neck is forming with body is essential to assess the accuracy of reduction thereby prevent malunion. This values are also important for kinesiology and anthropology. In the present study we report the morphometry of squatting facet in the talus with emphasis on anatomical co relation between presence of this facet with angles on the neck like angle of inclination and declination and there is no data available on such correlation.

\section{Materials and Methods}

Study was conducted on 125(right-64, left-61) dry tali irrespective of sex from Department of Anatomy, East Point College of Medical Science and Research Centre. Articular surface of talus on inferior surface is studied for various types of their incidence. Angle at the neck i.e angle of inclination and deviation were measured with the help of Goniometer. Squatting facets were observed as well. Difference in angle of inclination and declination with or without accessory facet were obtained by using student $t$ test method.

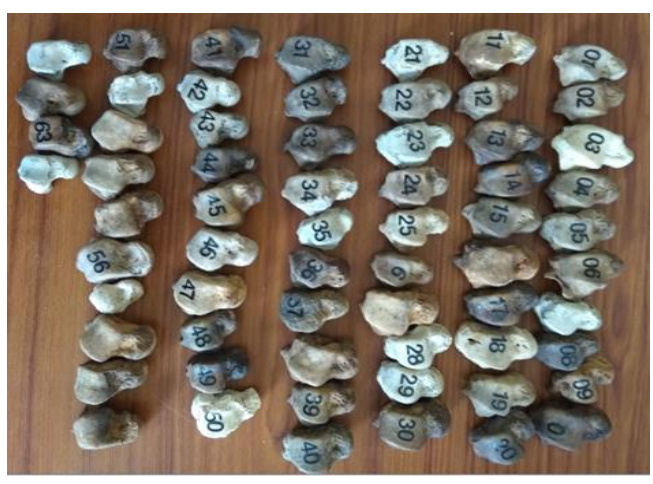

Fig. 4: Right tali

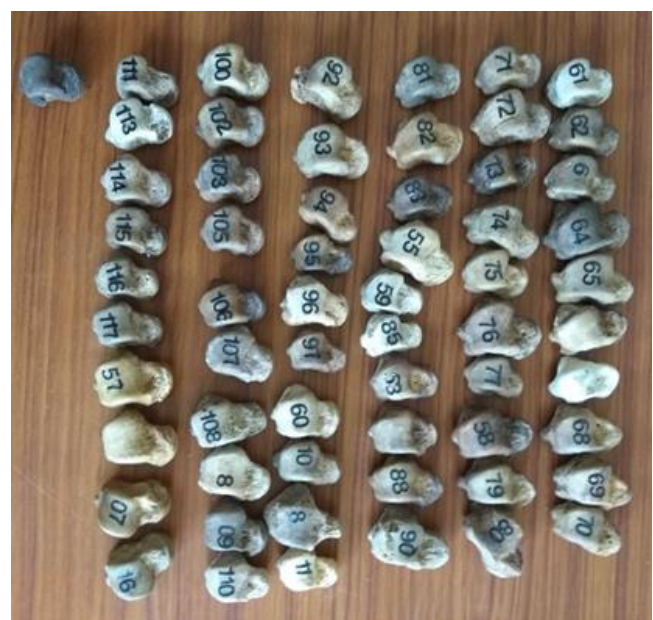

Fig. 5: Left tali 


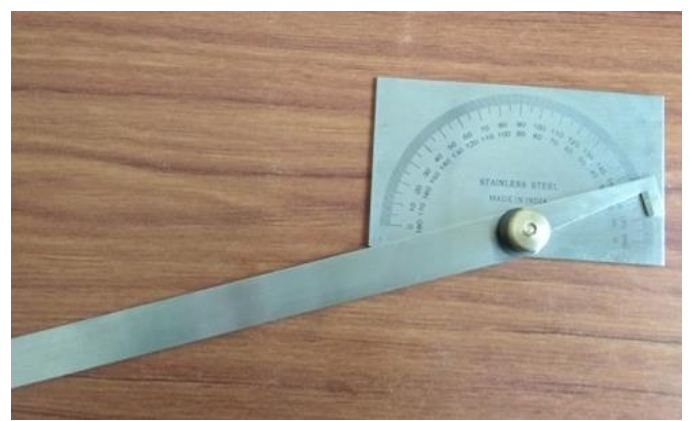

Fig. 6: Goniometer

\section{Results}

Table 1: Incidence of types of articular facets on tali

\begin{tabular}{|l|c|c|c|}
\hline \multicolumn{1}{|c|}{ Facets } & Right & Left & Total \\
\hline Type I & $13 \%$ & $21.80 \%$ & $17.60 \%$ \\
\hline Type II & $45 \%$ & $42 \%$ & $44 \%$ \\
\hline Type III & $34.40 \%$ & $31.20 \%$ & $32.80 \%$ \\
\hline Type IV & 0 & $3.12 \%$ & $1.60 \%$ \\
\hline Type Va & $2 \%$ & $0 \%$ & $1.60 \%$ \\
\hline Type Vb & $3.20 \%$ & $1.50 \%$ & $2.40 \%$ \\
\hline
\end{tabular}

Table 1 shows incidence of different types of articular facets on inferior surface of tali. Type II articular facets were highest in its incidence in our study with no difference in right and left side viz. $45 \%$ and $42 \%$ respectively. Second highest being Type III articular facet on talus without any difference on right and left side viz. $34.4 \%$ and $31 \%$ respectively. Type IV and Type $\mathrm{V}$ were least types of articular facet.

Table 2: Squatting facets on tali

\begin{tabular}{|l|c|c|c|}
\hline \multicolumn{1}{|c|}{ Side } & \multicolumn{2}{|c|}{ Present } & Absent \\
\hline & Medial & Lateral & \\
\hline Right & $0 \%$ & $44 \%$ & $66 \%$ \\
\hline Left & $0 \%$ & $37.50 \%$ & $62.50 \%$ \\
\hline
\end{tabular}

Not significant $\mathrm{p}$ value $>0.05$

Table 2 shows incidence of squatting facet. Lateral squatting facet was found in $44 \%$ of the bones on right side $37.5 \%$ on left side, showing no significant difference. In our study we did not find any medial squatting facet.

Table 3: Angle of Inclination and deviation

\begin{tabular}{|c|c|c|}
\hline Angles & Right & Left $p$ value \\
\hline Inclination $(\mathrm{M} \pm \mathrm{SD})$ & $125 \pm 4$ & $110 \pm 60.0025$ \\
\hline deviation $(\mathrm{M} \pm \mathrm{SD})$ & $26.3 \pm 3.1$ & $25.9 \pm 2.30 .07$ \\
\hline
\end{tabular}

$\mathrm{M}=$ Mean, $\mathrm{SD}=$ Standar d deviation

Table 3 shows mean highly significant incidence of angle of inclination on right side is 125 and on left side
110. Angle of deviation mean we found was 26.3 on right side and 25.9 on left side. We found no significant difference between angle on right and left side of talus.

Table 4: Angle of deviation and inclination with or without squatting facet

\begin{tabular}{|c|c|c|}
\hline Angles & squatting facet + & squatting facet - \\
\hline Deviation $(\mathrm{M} \pm \mathrm{SD})$ & Right $25.8 \pm 2.2$ & $26.1 \pm 2.4$ \\
\hline & Left $27.2 \pm 3.1$ & $25.7 \pm 3$ \\
\hline Inclination $(\mathrm{M} \pm \mathrm{SD})$ & Right $123 \pm 3.5$ & $95 \pm 5$ \\
\hline & Left118 12.5 & $100 \pm 3.2$ \\
\hline
\end{tabular}

$\mathrm{M}=$ Mean, $\mathrm{SD}=$ Standard deviation

Table 4 shows there is no significant co relation between angle of deviation and presence or absence of lateral squatting facet $\mathrm{p}$ value $>0.05$. With angle of inclination we found there is significant co relation between angle of inclination and squatting facet with $p$ value 0.003 . Indicating those tali where squatting facet was present, angle of inclination was larger significantly.

\section{Discussion}

Talus is a key bone in medial arch and acts as connecting link between tibia, fibula and foot. As compared to the weight bearing facet of pelvis, femur and tiblia articular facet on talus are very small in relation to loading environment and their ability to remain plastic during ontogeny represents an adaptation to the body weight gain during our development. Precise biometric measurements have contributed to analysis of functional consequences of talo calcaneo navicular joint. Modification of talus indicative of habitual squatting has been reported since pleistonic era. ${ }^{6}$ Result of prolonged extreme flexion at the ankle joint during squatting which is common in Indian population called as palti position, brings the modification on neck of talus characterizes the strong pressure and traction forces on ankle and talar joint.

In present study Type II showed highest incidence of $44 \%$. This observation is comparable with study done by Bilodi ${ }^{7}$ and Garg et $\mathrm{al}^{8}$ who observed $50 \%$ and $43.7 \%$ respectively. Though Arora et al ${ }^{9}$ observed highest incidence of typeI facets $78 \%$ and Kaur et $\mathrm{al}^{10}$ $24 \%$. In present study incidence of type II tali was more on the right side $45 \%$ as compared to left side $42.1 \%$, 
Garg et $\mathrm{al}^{8}$ observed $28.7 \%$ on right side and $48.7 \%$ on left side. Least Type of articular facet we found was type IV $1.6 \%$ and type Va $1.6 \%$ which is similar to study done by Garg et $\mathrm{al}^{8}$ (2013), and Bilodi, ${ }^{7}$ Kaur et al. ${ }^{10}$

Various reasons have been described for variations on calcaneal facets on talus, some being due to different races, types of gait, built of an individual, plane of living could be level surface/hilly areas. Some variations could be because of impact on position of axis of movement between Talus and Calcaneum resulting in different positions relative to load and force. Bruckner ${ }^{11}$ opined that 3 facets on talus makes it more stable and less mobile, 2 facets configuration would be more mobile and less stable. The one facet configuration is the most mobile since all the facets have blended into one making it least stable joint.

Table 5: Data of incidence of squatting facet

\begin{tabular}{|l|c|c|c|c|c|}
\hline Population & $\begin{array}{c}\text { Pfitzer }^{\mathbf{1 2}} \\
\text { (Europe) }\end{array}$ & Sewell $^{\mathbf{1 3}}$ (Egyptian) & Rao $^{\mathbf{1 4}}$ (Australian) & $\begin{array}{c}\text { Thomson }^{3} \\
\text { (Andaman) }\end{array}$ & $\begin{array}{c}\text { Present study } \\
\text { (Indian) }\end{array}$ \\
\hline No. of Tali & 840 & 1006 & 238 & 300 & 125 \\
\hline Medial & $0 \%$ & $19 \%$ & $1.20 \%$ & 0 & 0 \\
\hline Lateral & $1 \%$ & $8.60 \%$ & $33.60 \%$ & $28.60 \%$ & $44 \%$ \\
\hline
\end{tabular}

In our study incidence of lateral squatting facet is $44 \%$ similar to studies done in north Indian population done by Nishant ${ }^{15}$ et al $50 \%$. Medial facets were not found in our study but in their study it was doubtful $(1.8 \%)$. The occurrence of lateral squatting facet is similar to Andaman population but less in European, Egyptian and Australian population as shown in table V. This dissimilarity in the occurrence of squatting facet could be because of various factors like squatting posture, prolonged standing and walking on land surfaces like flat or uneven. Therefore extreme dorsiflexion is not only the reason in occurrence of squatting facet but also the above mentioned changes which results in lateral deviation of foot causing more contact of lateral surface of neck of talus with anterolateral margin of malleolar surface of talus.

Table 6: Data of mean values of angle of inclination (AI) and angle of deviation (AD) in various studies

\begin{tabular}{|l|c|c|c|c|}
\hline Population & Motagi $^{\mathbf{1 6}}$ (Indian) & Paturat $^{\mathbf{1 7}}$ (Europe) & Sarafian $^{\mathbf{1 8}}$ (American) & Present study $^{\text {AD }}$ \\
\hline AD & 26.5 & $22-30$ & 24 & 25 \\
\hline AI & 121 & 115 & 114 & 125 \\
\hline
\end{tabular}

In this study mean angle of deviation was 25 and angle of inclination was 125 which are similar to study done by Motagi et $\mathrm{al}^{16}$ but in his study, for AI there was no difference on right and left side tali could be due to smaller sample size. In our study AI on right side was significantly high as compared to left side tali, depicting functional adaptability of medial arch to stress on the right foot. Which could be due to unequal body weight ditribuation. Table VI depicts the angles studied by various authors

Statistical analysis of present study showed no significant co relation between presence of squatting facet and angle of declination and there were tali with lateral squatting facet, which had significant larger AI in comparison with those without the facet. We concluded that this modification on neck of talus is attributed to unequal distribution of body weight towards lateral side of neck of talus under the influence of climbing. We also infer that squatting facet develops in the talus with more angle of inclination leading to tali with higher curvature which results in pes cavus.

\section{Conclusion}

Differences in the articular facets on inferior surface of tali is attributed to the significance related to safety of joint i.e. presence of three facets make the joint more stable. Modification on neck of tali leading to formation of squatting facet reflects life style, habitual activities and postural adaptation of population. Occurrence of squatting facet is not only because of postural adaptation like squatting position due to extreme dorsiflexion, but also attributed to climbing, prolonged standing and pes cavus in the individuals. These variations can be used, for assessing the joints before surgery, as anthropological marker for racial and regional differences and in forensic sciences also. These modifications offer a basis to study the differences between past and contemporary population and also shows the daily activity of life and cultural structure.

\section{References}

1. Verhagen FD. "Arthritis of the subtalar joint associated with sustentaculum tali facet configuration". Journal of Anatomy. 1993;183:631-634.

2. Rohin Garg, Suhila Shekhwat, Khushboo Morga, Santosh Kumar. "Modification on dorsum of neck of talus (squatting facet and trochlear extensions) in Indians". Acta Medica International Journal. 2018;1:100-104.

3. Thomson A. "The Influence of Posture on the Form of the Articular Surfaces of the Tibia and Astragalus in the different Races of Man and the Higher Apes". J Anat Physiol. 1889;23(Pt 4):616-639. 
4. Charles R H. "The Influence of Function, as Exemplified in the morphology of lower extremity of Punjabi". Journal of anatomy and Physiology. 1893;2:271-280.

5. Laureut M, Chrostopher B, Yaowalak C. Talar morphology, phylogenetic affinity and locomotar adaptation of large oidiedamphtecid primate from middle ecocene of Myanmar. Amercican Journal of anthrolpology. 2010;143(2):208-22.

6. Oygucu IH, Kurt MA, Ikiz I, Erem T, Davies DC. Squating facets on the neck of the talus and extensions of the trochlear surface of the talus in Late Byzantine males. J Anat. 1998;192:287-291.

7. Bilodi AK. Study of calcaneal Articular facets in human tali". Medical Journal of Kathmandu University. 2003;2(3):213-215.

8. R .Garg, S Babuta, K Mogra, R Prsahar, S Shekawat: "Study on variation in pattern of calcaneal articular facet in human tali". People's $J$ of scientific Research. 2013;6(2):19-23.

9. Arora AK, Gupta SC, Gupta CD, Jeyasing P. "Variations in calcaneal articular facets in Indian tali". Anat Anz, 1979;(46):377-380.

10. Kaur M, Kalsey G, Laxmi V: "Morphological classification of tali on the basis of calcanean articular facets". PB Journal of Orthopedics. 2011;12(1):57-60.

11. Bruckner JS. "Variations in the Human Subtalar Joint. Journal of Orthopaedic \& Sports Physical Therapy." 1987;8(10):489-494.

12. Pfitzner W. "Beitrdge zur kenntniss desnienschlishen extremitatenskelets VII" morphology, Arbeiten hrsg. V. G. Schwalbe, VI, (1896) page 245.
13. Sewell Rbs. A Study of the Astragalus. J Anat Physiol. (1904);38(Pt 4):423-434.

14. Rao PDP. Squatting facets on the talus and tibia in Australian aborigines. Archeology and Physical Anthropology in Oceania. 1966;1;51-56.

15. Nishtha Singh, Alok K Singh, Ranjeet Kumar, Krishna Tiwari. 'Re-modeling of north Indian talus: A pressure effect of squatting position." MOJ Anatomy and Physiology. 2016;2(6):00067.

16. Motagi MV, Kottapurath SR, Dharwadkar Kavitarati."Morphometric analyses of human dry tali of South Indian origin" International Journal of Medical Science and Public Health. 2015;4(2):237-40.

17. Paturet G. Traite d Anatomie Humaine, Vol. 2. Paris: Masson, 1951

18. Sarrafian SK. Anatomy of the Foot and Ankle: Descriptive, Topographic, functional. Philadelphia, PA: Lippincott. 1983;400-7.

How to cite this article: Azra M, Prabhu A, Balachandra N. An anatomical study on types of calcaneal facets on talus and co relation between squatting facets and angles of neck. Indian J Clin Anat Physiol. 2018;5(4):434-438. 